\title{
Are higher unintended pregnancy rates among minorities a result of disparate access to contraception?
}

\author{
Michele Troutman', Saima Rafique ${ }^{2}$ and Torie Comeaux Plowden ${ }^{3^{*}}$
}

\begin{abstract}
Unintended pregnancy is a major global issue. Women who experience an unintended pregnancy have a significant risk of morbidity and mortality. Additionally, these women also experience substantial financial hardships. Many women, particularly women of color, do not have adequate access to reliable and affordable contraception resulting in major health disparities among this group. This review explores the relationship between unintended pregnancy and inadequate access to contraception and is divided into 5 sections: addressing problems associated with unintended pregnancies, unintended pregnancy rate in the US, disparities of unintended pregnancy rates and access to care, addressing potential solutions, and finally conclusions.
\end{abstract}

Keyterms: unintended pregnancy, healthcare disparities, contraception, access to care.

\section{Introduction}

An unintended pregnancy is any unplanned, mistimed or unwanted pregnancy at the time of conception [1]. In 2011, 48\% of all pregnancies in the United States were unintended [2]. Similarly, women worldwide have high unintended pregnancy rates. In $2010-2014,44 \%$ of all pregnancies worldwide were unintended [3]. Although we've begun to see a slow decline in these numbers with the aid of education, LARC methods, and access to family planning services, unintended pregnancy rates remain a major public health problem.

Unintended pregnancies have a substantial impact on public health. Women with unintended pregnancies have a higher percentage of late entry to care, alcohol and drugs use during pregnancy and higher rates of preterm birth [4]. Unintended pregnancies are often higher among adolescents, lower income, minority, and single women who have poverty rates twice that of other

\footnotetext{
* Correspondence: torie.c.plowden.mil@mail.mil

The views expressed herein are those of the authors and do not reflect the official policy or position of the US Army Medical Department, Department of the Army, Department of Defense, or the US Government.

${ }^{3}$ Department of Obstetrics and Gynecology, Womack Army Medical Center, Ft Bragg, NC, USA

Full list of author information is available at the end of the article
}

groups, making the financial impact of an unplanned conception even greater [5]. Improved access to contraception by age 20 has been shown to decrease the likelihood that a woman will subsequently live in poverty and thus increase one's quality of life [6]. With the onset of coronavirus disease 2019 (COVID-19) and the resurface of a national economic depression, it is important that now more than ever we consider the economic burden of these unintended pregnancies and the strain on national resources. Many organizations are significantly decreasing in-person and telehealth visits and reproductive access organizations have been forced to innovate in a more thoughtful way to reach those most at risk. There are slated state and national healthcare budget cuts although it remains unclear the long-term effects it will have on unintended pregnancies. While it is possible to increase clinic show rates with the use of technology and decreasing economic barriers, what remains is the constant gaping disparities in digital equity and patient perception regarding the care, or lack thereof, that they're receiving.

Unintended pregnancy is a public health emergency. The U.S. Department of Health and Human Services has identified reducing unintended pregnancy as a significant 
goal in the Healthy People 2020 family planning objectives. The initiative focuses on improving pregnancy planning, spacing and prevention as a way to improve health outcomes while decreasing the economic burden. In order to accomplish the goal, barriers such as limited access to publicly funded services, limited transportation, lack of youth-friendly services, and inadequate services for men are identified as some of the issues to be addressed [7].

Although women of reproductive age of all races and ethnicities are at risk of unintended pregnancy, Hispanic and Black women are disproportionally at risk [8]. Globally, the at-risk population numbers are in the millions, making this a critical issue worldwide. Contributions to this disparity include income, insurance status, relationship status, and education level. Our objective was to examine the contributors to high rates of unintended pregnancies and to identify potential strategies to address this critical issue.

\section{Unintended pregnancy rates in America}

In 2011, the rates of unintended pregnancy among African-American, Hispanic and Caucasian women that ended in birth were 33,31 , and $17 \%$ respectively in the United States [2]. Using data from the National Survey of Family Growth from 2006 to 2010, Kim et al. observed $50 \%$ of the 3577 pregnancies were unintended [9]. The study notes that women of color, particularly black women had higher rates than whites; 63\% (Black women), 48\% (Hispanic women) and $42 \%$ (Caucasian women). Although the rates were higher among black and Hispanic women, the difference was not statistically significant (Fig. 1). However, even the lowest rate of unintended pregnancy, $42 \%$, would be considered unacceptable high by most healthcare providers. This number is particularly alarming given the failure rate of less than $1 \%$ for highly effective contraceptives [10].

\section{Disparities in unintended pregnancy and access to care}

The medical literature has documented racial and ethnic disparities in access to healthcare, as well the quality of that care for more than a decade. In 2003, the Institute of Medicine determined "research suggests that healthcare providers' diagnostic and treatment decisions, as well as their feelings about patients, are influenced by patients' race or ethnicity and that these differences may contribute to disparities in health outcomes" [11]. Multiple studies have unfortunately demonstrated that African-American and Latina women from low socioeconomic backgrounds have been strongly encouraged to limit their family sizes and have been pressured to start contraception or proceed with tubal sterilization $[12,13]$.

Historically, the United States has had a shameful history regarding forced sterilizations and reproductive injustices which may lead minority women to be distrustful of contraception $[14,15]$. There are also racial differences in contraceptive preferences. Because it is important to many African American women to avoid the use of hormones, they may be less likely to choose highly effective contraception such as implants, injectable contraception or levonorgestrel containing intrauterine devices (IUDs) [15]. Outside of preferences

\section{Unintended Pregnancy and Race}

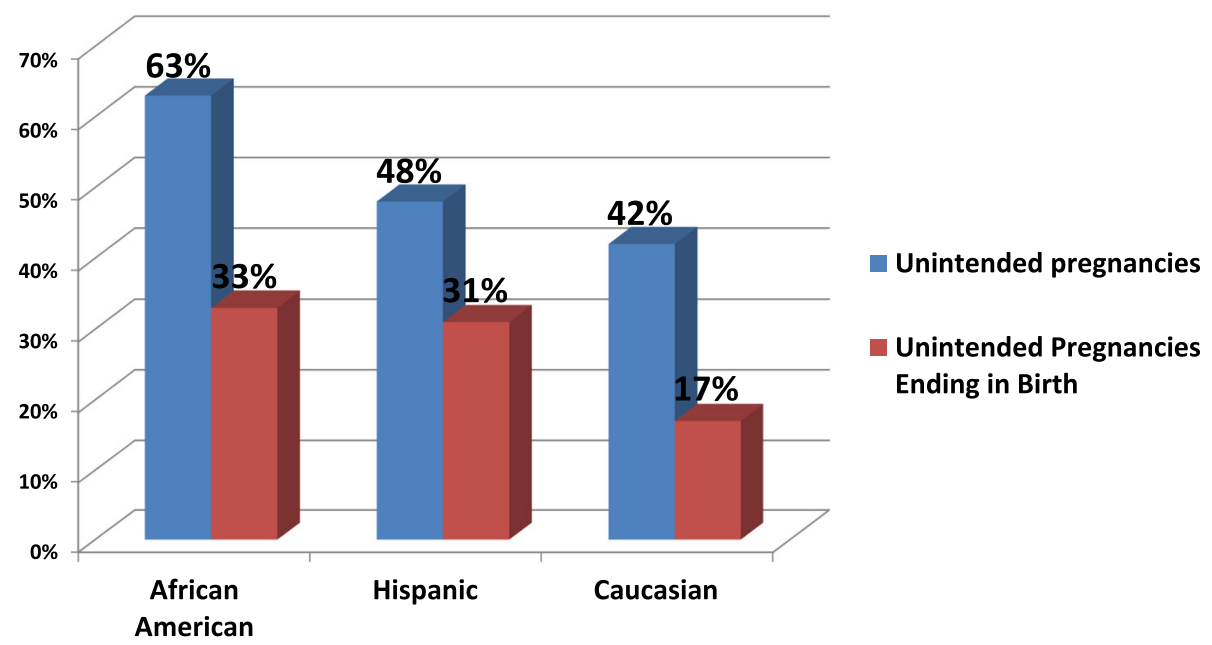

Adapted from Kim etal Am J of Prev Med 2015

Fig. 1 Unintended pregnancy and race 
guided by historical weight, there are also distinctive barriers to reproductive access.

This idea of disparity in contraceptive access is echoed in the discordance between desired fertility and chosen method of contraception. A study of 110 (48 AfricanAmericans, 43 Hispanics, 19 Caucasians) low-income women who lived in an underserved area found that $40 \%$ of women who did not desire pregnancy had unprotected intercourse within the last 12 months [16]. Similarly, a study examining contraception trends found that $16 \%$ of African-American women who were at risk of unintended pregnancy were not using contraception compared to about 9\% of Hispanic, white and Asian women [8].

Attitudes and norms regarding contraception in minority groups are often different than those of Caucasian women. Frequently, when African-American and Latina women choose contraception, they choose less effective contraception options (i.e. condoms) compared to white women [12-14]. Interestingly, data from the contraceptive $\mathrm{CHOICE}$ project revealed that prior to enrollment in the study, African-American women who have had a history of discrimination were more likely to choose less efficacious contraceptive measures (specifically barrier methods, natural family planning and withdrawal) but after enrollment, $67 \%$ of these women elected to use long-acting reversible contraception (LARC) [16]. The script that was used in the CHOICE study provided important information about the effectiveness of various contraceptive methods, and patients were free to choose whatever method they desired. Patient education played a pivotal role in the success of the CHOICE project, but it is imperative that other contraceptive programs provide education and not coercion.

High unintended pregnancy rates, particularly among low-income women and women of color, have persisted despite the expanded options for highly efficacious contraceptives. LARC, which includes IUDs and subdermal contraceptive implants, are cost-effective and highly efficacious, with an annual failure rate of $0.05 \%$ (implants) and $0.2-0.8 \%$ (IUDs) [17]. Despite the efficacy of these methods, they are often associated with up-front out-ofpocket costs which may be prohibitive to poorer women $[10,17]$. When women were given multiple options for contraception, and cost was not a consideration, 67\% elected to use long-acting reversible contraceptive (LARC) [18]. In comparison, non-LARC contraceptive options were 20 times more likely to have an unintended pregnancy, demonstrating how much effective contraception is of paramount importance for preventing unintended pregnancy [19].

Any efforts to decrease unintended pregnancy will need to include elimination of barriers such as a lack of insurance, inadequate coverage that requires large out of pocket expenses, or extremely high premiums. One potential strategy is to educate third party payers about the cost savings associated with widely available contraception. One study estimated that the direct medical cost of unintended pregnancy in the United States was more than $\$ 4.6$ billion annually [20]. Women ages $18-24$ have the highest risk of unintended pregnancy. Using cost models, one review found that if $10 \%$ of women ages 20 29 who used oral contraception changed to LARC, the total costs associated with unintended pregnancy would decrease by $\$ 288$ million per year [20]. Third party payers should consider access to contraception as effective preventive health care that will decrease medical costs.

Although decisions regarding contraception are often left up to the female partner, the role of the male partner must be examined as part of the strategy to decrease unintended pregnancy. Utilizing data from the 2006-2010 National Survey of Family Growth, one study attempted to better understand knowledge of contraception among young men [21]. Researchers found that although 96.6\% of men reported formal sex education, Black men were less likely to receive contraceptive education [21]. Another study examining contraceptive knowledge found that men were more likely to "display serious gaps in objective knowledge about the major contraceptive options" [22]. Despite men often being left out of conversations involving contraception, counseling that reflects a couple's culture and values may help increase compliance especially amongst minority groups [23].

Age plays a significant role in the likelihood of having an unintended pregnancy. Young women who become sexually active at an early age are particularly at risk for an unplanned conception. Data from Demographic and Health Surveys revealed that a significant proportion of adolescents in 16 countries reported sexual activity. In 9 of these 16 countries, approximately $40 \%$ of women reported sexual activity before age 18 while men engaging in intercourse before age 18 ranged from 25 to $75 \%$ [24]. There is a clear need for access to contraception among adolescents in many of these countries. However, adolescents in low and middle-income countries face additional barriers regarding contraception. These include poor understanding of how to use various methods correctly and law or policies preventing young unmarried women from accessing contraception [24]. The following recommendations are potential solutions to the disparities of contraception access facing minority population.

\section{Addressing the problem: potential solutions [Table 1]}

The Centers for Disease Control (CDC) recommends that "every woman, man and couple should be encouraged to have a reproductive life plan" [25]. 
Table 1 Strategies to Decrease Unintended Pregnancy

\section{Strategies to Decrease Unintended Pregnancy}

\begin{tabular}{|l|l|}
\hline Strategy & Example \\
\hline Increase Access & Universal Health Coverage \\
\hline Decrease Cost & $\begin{array}{l}\text { Negotiation by large health care } \\
\text { organizations for lower prescription costs } \\
\text { Use of generic prescriptions }\end{array}$ \\
\hline Increase Cultural Sensitivity & $\begin{array}{l}\text { Education of Health Care Providers and } \\
\text { Patients }\end{array}$ \\
\hline Education of Providers & $\begin{array}{l}\text { Incorporation of contraceptive education } \\
\text { in medical school, nursing school } \\
\text { pharmacy school and residency }\end{array}$ \\
\hline curriculum
\end{tabular}

\section{Access/cost}

Although multiple factors affect the unintended pregnancy rate, access to reliable and safe contraception can certainly positively impact this problem. Universal coverage of all contraceptive methods has been shown to decrease unintended pregnancy rates [12]. Negotiation with pharmaceutical companies by large health care organizations, such as HMOs, is also a potential strategy to decrease cost. On a global level, organizations like the Gates Foundation are investing in reasons for non-use, distribution and development for contraceptive technology [26].

\section{Culturally sensitive approach}

African-American and Latina women suffer from misconceptions surrounding contraception, its use and efficacy [14]. The CHOICE project serves an example of using patient education to effectively overcome cultural beliefs that pose a barrier to the use of highly efficacious contraception. Access to care limitations based upon race, ethnicity and income is well documented and poses one of the most significant impediments to contraceptive access. Incorporation of contraceptive education as well as culturally sensitivity training into the curriculum of medical, nursing, and pharmacy schools and residency training programs are a tool that can be used to address these important issues.

\section{Appropriate physician education}

Like patients, health care professionals often have limited knowledge about the availability and appropriate use of contraceptive methods. IUD use, one type of LARC, has been hampered by the persistence of incorrect myths including that they are contraindicated in young/adolescent nulliparous women, they lead to infertility and women will experience high rates of infection [17]. Residency programs in obstetrics/gynecology, family practice and pediatrics along with nurse practitioners and physician assistants should ensure that providers are aware and well-educated about LARC methods and its contraindications. Appropriate counseling by providers "not only promotes effective methods but also directly translates to increased use" [14]. Use of published materials by organizations such as the American College of Obstetricians and Gynecologists (ACOG), Society of Family Planning (SFP), and the use of apps such as Medical Eligibility Criteria app produced by the CDC (https://www.cdc.gov/reproductivehealth/contraception/ usmec.htm) facilitate the appropriate selection of contraceptives for women with medical conditions such as hypertension. These tools aid women in locating effective contraception that they otherwise could have been denied as a result of a provider's fears about medical complications.

\section{Maximizing opportunities to educate patients}

The ACOG strongly advocates for reproductive planning. In a recent committee opinion, the College emphasized that physicians should take every contact with their patients as a teachable moment [27]. Rather than limiting the discussion of contraceptive management to well women or contraceptive visits, every visit should be 
considered as a unique opportunity to address patient's reproductive plan and offer counseling, education and correct any misconceptions on available contraceptive options. Initiatives like "One Key Question" and "Providing Quality Family Planning Services" aim to enhance effective communication and improve understanding of a woman's reproductive health plan [28]. Adopting these strategies in day-to-day interactions will efficiently utilize available resources and further achieve the goal of preventing unintended pregnancies [29].

\section{Empowering other health care providers}

Emergency contraceptives is another excellent option geared towards decreasing the unintended pregnancy rates [30]. Now that these methods are available over the counter, many patients may seek advice from pharmacists [31]. Pharmacists can advise patients of emergency contraception, but, additionally can provide information regarding LARC and refer to an appropriate provider [31]. Nurse practitioners are becoming the primary providers of contraception for some women. Training these healthcare providers to provide not only counseling about LARC, but also placement of IUD and implants will help women access these methods more easily [31].

\section{Using community resources}

Disseminating information through various avenues including schools, health centers, the media, and peer education has been shown to improve uptake of LARC use [31]. Additionally, other resources that should be considered when targeting minority groups may include churches, community center, and salons. One limitation of LARC use is a lack of appropriately trained personnel. Charyeva et al. in their study in Northern Nigeria showed increased utilization of LARCS by training community health extension workers in their insertion and removal [32]. In Ethiopia, similar results were noted in the utilization of implants with the help of health extension workers [33]. These studies suggest that optimizing human resources and training ancillary staff to deliver these services could be another option in increasing the utilization of contraceptives and eventually decreasing unintended pregnancies in at risk communities worldwide.

\section{Title $X$ and reproductive access}

Title $\mathrm{X}$ is a federal grant program through the US Department of Health and Human Services that provides comprehensive family planning and preventative health services, prioritizing low income families [34]. Recent proposed revisions to Title $\mathrm{X}$ will negatively impact access to legal abortion services and impede the provider's ability to discuss family planning options at federally funded centers. The regulations would most affect low income and minority women. Organizations like Planned Parenthood who serve $41 \%$ of Title X recipients, use funding to provide preventative services and prevent 1 million unintended pregnancies a year [35]. If these regulations are enacted, low income and minority women who rely on Title X centers for their reproductive needs will be much more vulnerable to unintended pregnancies.

\section{Conclusion}

Unintended pregnancy continues to be a critical global issue, particularly among certain ethnic and racial groups as well as low income women. These unintended pregnancies can negatively impact women physically, emotionally, and financially. Easier access to effective contraception methods, particularly long-acting reversible contraception, can certainly help to address this public health issue. Physicians and other health-care providers need to ensure they are providing comprehensive care and have received appropriate contraceptive education as well as culturally sensitive training. Although access to contraception plays a large role in unintended pregnancy, the added impact of less efficacious contraceptive methods use, lack of patient and provider education and understanding are additional contributors. Contraceptive programs must utilize multiple wide ranging strategies to achieve success in decreasing unintended pregnancies and its surrounding disparities.

\section{Abbreviations \\ COVID-19: Coronavirus disease 2019; IUD: Intrauterine device; LARC: Long acting reversible contraception; CDC: Centers for disease control; \\ ACOG: American college of obstetricians and gynecologists; SFP: Society of family planning}

\section{Acknowledgements}

The authors would like to acknowledge Dr. Alicia Christy for her feedback and critique of this manuscript.

Authors' contributions

MT, SR and TCP contributed to the writing of this manuscript. All authors read and approved the final manuscript.

Funding

Not applicable.

Availability of data and materials

Not applicable.

Ethics approval and consent to participate

Not applicable.

Consent for publication

Not applicable.

Competing interests

The authors declare that they have no competing interests.

Author details

${ }^{1}$ Department of Obstetrics and Gynecology, Beth Israel Deaconess Medical Center, Boston, MA, USA. ${ }^{2}$ Advantia Ob/Gyn Shady Grove, Rockville, MD, USA. ${ }^{3}$ Department of Obstetrics and Gynecology, Womack Army Medical Center, Ft Bragg, NC, USA. 
Received: 25 September 2019 Accepted: 30 July 2020

Published online: 01 October 2020

\section{References}

1. Brown SS, Eisenberg L, Institute of Medicine (U.S.). Committee on Unintended Pregnancy. The best intentions: unintended pregnancy and the well-being of children and families. Washington, D.C.: National Academy Press; 1995. ix, 380 p. p.

2. Finer LB, Zolna MR. New England journal of medicine 2016; 374:843-852 March 3, 2016. DOI: https://doi.org/10.1056/NEJMsa1506575.

3. Bearak J, Popinchalk A, Alkema L, Sedgh G. Global, regional, and subregional trends in unintended pregnancy and its outcomes from 1990 to 2014: estimates from a Bayesian hierarchical model. Lancet Glob Health. 2018;6(4): e380-9. https://doi.org/10.1016/S2214-109X(18)30029-9.

4. Haider S, Stoffel C, Donenberg G, Geller S. Reproductive health disparities: a focus on family planning and prevention among minority women and adolescents. Glob Adv Health Med: Improving Healthc Outcomes Worldwide. 2013:2(5):94-9 PubMed PMID: 24416701. Pubmed Central PMCI D: 3833575

5. Census Bureau US. Income, poverty, and health insurance coverage in the United States. In: Current population reports Consumer income P60. Washington, D.C.: Bureau of the Census.

6. Browne SP, LaLumia S. The effects of contraception on female poverty. Policy Anal Manage: [the J Assoc Public Policy Anal Manage]. 2014;33(3): 602-22 Summer. PubMed PMID: 24988652.

7. U.S. Department of Health and Human Services. Healthy People 2020 topics and objectives Washington, DC.2010 [March 14, 2016]. Available from: https://www.healthypeople.gov/2020/topicsobjectives2020/objectivelist. aspx?topicid $=13$

8. Mosher WD, Jones J, Abma JC. Intended and unintended birth in the United States: 1982-2010. Natl Health Stat Rep. 2012;24(55):1-28 PubMed PMID: 23115878

9. Kim TY, Dagher RK, Chen J. Racial/ethnic differences in unintended pregnancy: evidence from a national sample of U.S. women. Am J Prev Med. 2016:50(4):427-35.

10. Wilder V, Bromfield G, de Fiebre G, Prine L. Disparities in contraceptive care. J Health Care Poor Underserved. 2014:25(2):451-9 PubMed PMID: 24858860

11. Smedley BD, Stith AY, Nelson AR, Institute of Medicine (U.S.). Committee on Understanding and Eliminating Racial and Ethnic Disparities in Health Care. Unequal treatment: confronting racial and ethnic disparities in health care. Washington, D.C.: National Academy Press; 2003. xvi, 764 p.

12. Dehlendorf C, Rodriguez MI, Levy K, Borrero S, Steinauer J. Disparities in family planning. Am J Obstet Gynecol. 2010;202(3):214-20 PubMed PMID: 20207237. Pubmed Central PMCID: 2835625

13. Ayoola $\mathrm{AB}$, Zandee $\mathrm{GL}$, Johnson E, Pennings K. Contraceptive use among low-income women living in medically underserved neighborhoods. J Obstet Gynecol Neonatal Nurs. 2014;43(4):455-64 PubMed PMID: 24958447.

14. Casey F, Gomez-Lobo V. Disparities in contraceptive access and provision. Semin Reprod Med. 2013;31(5):347-59 PubMed PMID: 23934695.

15. Borrero S, Schwarz EB, Creinin M, Ibrahim S. The impact of race and ethnicity on receipt of family planning services in the United States. J Women's Health. 2009;18(1):91-6 PubMed PMID: 19072728. Pubmed Central PMCID: 2743980

16. Kossler K, Kuroki LM, Allsworth JE, Secura GM, Roehl KA, Peipert JF. Perceived racial, socioeconomic and gender discrimination and its impact on contraceptive choice. Contraception. 2011;84(3):273-9 PubMed PMID: 21843693. Pubmed Central PMCID: 3539813.

17. Parks C, Peipert JF. Eliminating health disparities in unintended pregnancy with long-acting reversible contraception (LARC). Am J Obstet Gynecol. 2016;214(6):681-8

18. Secura GM, Allsworth JE, Madden T, Mullersman JL, Peipert JF. The contraceptive $\mathrm{CHOICE}$ project: reducing barriers to long-acting reversible contraception. Am J Obstet Gynecol. 2010;203(2):115 e1-7 PubMed PMID: 20541171. Pubmed Central PMCID: 2910826

19. McNicholas C, Madden T, Secura G, Peipert JF. The contraceptive CHOICE project round up: what we did and what we learned. Clin Obstet Gynecol. 2014;57(4):635-43 PubMed PMID: 25286295. Pubmed Central PMCID: 4216614.

20. Trussell J, Henry N, Hassan F, Prezioso A, Law A, Filonenko A. Burden of unintended pregnancy in the United States: potential savings with increased use of long-acting reversible contraception. Contraception. 2013; 87(2):154-61 PubMed PMID: 22959904. Pubmed Central PMCID: 3659779.

21. Farkas AH, Vanderberg R, Sucato GS, Miller E, Akers AY, Borrero S. Racial and ethnic differences in young men's sex and contraceptive education. J Adolesc Health. 2015;56(4):464-7 PubMed PMID: 25797633. Pubmed Central PMCID: 4371132

22. Frost JJ, Lindberg LD, Finer LB. Young adults' contraceptive knowledge, norms and attitudes: associations with risk of unintended pregnancy. Perspect Sex Reprod Health. 2012;44(2):107-16 PubMed PMID: 22681426.

23. Warren JT, Harvey SM, Bovbjerg ML. Characteristics related to effective contraceptive use among a sample of nonurban Latinos. Perspect Sex Reprod Health. 2011;43(4):255-62

24. Chandra-Mouli V, McCarraher DR, Phillips SJ, Williamson NE, Hainsworth G. Contraception for adolescents in low and middle income countries: needs, barriers, and access. Reprod Health. 2014:11(1):1 PubMed PMID: 24383405. Pubmed Central PMCID: 3882494

25. Johnson K, Posner SF, Biermann J, Cordero JF, Atrash HK, Parker CS, et al. Recommendations to improve preconception health and health care-United States. A report of the CDC/atsdr preconception care work group and the select panel on preconception care. MMWR Recomm Rep. 2006; 55(RR-6):1-23 PubMed PMID: 16617292

26. Family Planning: Strategy overview. Gates Foundation 2020. Retrieved from www.gatesfoundation.org

27. Committee Opinion No. 654: Reproductive life Planning to reduce unintended pregnancy. Obstet Gynecol 2016;127(2):e66-9. PubMed PMID: 26942389

28. Bellanca HK, Hunter MS. ONE KEY QUESTION(R): preventive reproductive health is part of high quality primary care. Contraception. 2013;88(1):3-6 PubMed PMID: 23773527.

29. Gavin L, Moskosky S, Carter M, Curtis K, Glass E, Godfrey E, et al. Providing quality family planning services: recommendations of CDC and the U.S. office of population affairs. MMWR Recomm Rep. 2014;63(RR-04):1-54 PubMed PMID: 24759690.

30. Devine KS. The underutilization of emergency contraception. Am J Nurs 2012:112(4):44-50 quiz 1-2. PubMed PMID: 22421320.

31. Shoupe D. LARC methods: entering a new age of contraception and reproductive health. Contracept Reprod Med. 2016:2(4).

32. Charyeva Z, Oguntunde O, Orobaton N, Otolorin E, Inuwa F, Alalade O, et al Task shifting provision of contraceptive implants to community health extension workers: results of operations research in northern Nigeria. Glob Health Sci Pract. 2015;3(3):382-94 PubMed PMID: 26374800. Pubmed Central PMCID: 4570013

33. Asnake M, Henry EG, Tilahun Y, Oliveras E. Addressing unmet need for longacting family planning in Ethiopia: uptake of single-rod progestogen contraceptive implants (Implanon) and characteristics of users. Int J Gynecol Obstet. 2013:123(Suppl 1):e29-32 PubMed PMID: 24035007.

34. HHS.gov. (2019). Funding History. Available at: https://www.hhs.gov/opa/ title-x-family-planning/about-title-x-grants/funding-history/index.html.

35. Planned Parenthood Action Fund. Title X: Affordable Birth Control and Reproductive Health Care. Retrieved from http://www. plannedparenthoodaction.org/issues/health-care-equity/title-x.

\section{Publisher's Note}

Springer Nature remains neutral with regard to jurisdictional claims in published maps and institutional affiliations.

Ready to submit your research? Choose BMC and benefit from:

- fast, convenient online submission

- thorough peer review by experienced researchers in your field

- rapid publication on acceptance

- support for research data, including large and complex data types

- gold Open Access which fosters wider collaboration and increased citations

- maximum visibility for your research: over $100 \mathrm{M}$ website views per year

At BMC, research is always in progress.

Learn more biomedcentral.com/submission 